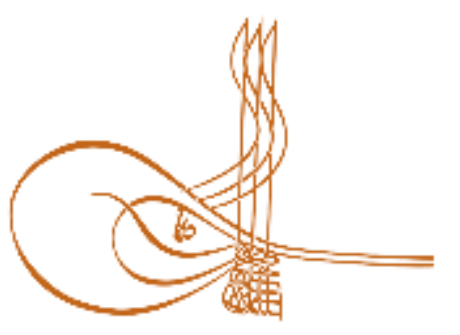

www.turkishstudies.net/turkishstudies
Turkish Studies

eISSN: $1308-2140$

Research Article / Araştırma Makalesi

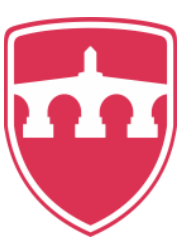

INTERNATIONAL

BALKAN

UNIVERSITY

Sponsored by IBU

\title{
Halk Eğitim Merkezlerindeki Derslerde “Öğrenen Kontrolü Stratejisinin” Kullanımı -Kahramanmaraş İli Örneği-
}

\author{
The Use of "Learner Control Strategy" in Courses of Public Education Centers
}

- The Sample of Kahramanmaraş Province-

\author{
M. Oğuz Kutlu* - Asım Yapııı* ${ }^{*}$ Sevim Sivik ${ }^{* * *}-$ Ceylan Yılmaz ${ }^{* * * *}$
}

\begin{abstract}
As Reigeluth and Stein (1983:338) believe that when considering the instructional science, it is related to understanding and enlarging methods of instructions so that those methods can be made more effective, more efficient and appealing. In 1983, Developed by Reigeluth-Merill, The Elaboration Theory of Instruction's main purpose is to extend in Merrill's Component Display Theory (CDT) to the macro level (i.e. to such concerns as selection, sequencing, synthesizing, and systematic review of related ideas) in other words, its purpose is to integrate as much as possible of our current knowledge about learning and istruction on the on the macro level (Reigeluth and Stein, 1983:337). On the other hand, according to Reigeluth and Stein (1983:362) the elaboration theory affords possibilities for learner control over the selection of content (1), instructional-strategy component (3), and cognitive strategies (4), the second category, pace, is only controllable at the micro level) The general purpose of this research is to determine the level of "Learner Control Strategy" used by educators (master trainers) working in Public Education Centers in their courses. This research is designed as a descriptive study is survey model (Karasar, 2006:77). The participitans of the research was formed; In the 2018-2019 academic year, from 129 educators working in Onikişubat and
\end{abstract}

\footnotetext{
* Doç. Dr., Çukurova Üniversitesi, Eğitim Fakültsi, Eğitim Bilimleri Bölümü Assoc. Prof. Dr., Cukurova University, Faculty of Education, Department of Educational Sciences ORCID 0000-0002-6539-2354

okutlu@cu.edu.tr

${ }_{* *}^{*}$ Prof. Dr., Ankara Sosyal Bilimler Üniversitesi, İslami İlimler Fakültesi, Felsefe ve Din Bilimleri Bölümü Prof. Dr., Ankara Social Sciences University, Faculty of Islamic Sciences, Department of Philosophy And Religion ORCID 0000-0002-7041-9064 asim.yapici@asbu.edu.tr

**** Doktora Öğrencisi, Cukurova Universitesi, Sosyal Bilimler Enstitüsü, Eğitim Bilimleri ABD

Ph.D. Student, Cukurova University, Institute of Social Sciences, Department of Educational Sciences ORCID 0000-0001-7756-6932

sevim-hanife@hotmail.com

***** Öğr. Gör. Siirt Üniversitesi, Sosyal Bilimler Meslek Yüksek Okulu, Yabancı Diller ve Kültürler Bölümü Instructor, Siirt University, Vocational School of Social Sciences, Department of Foreign Languages and Cultures ORCID 0000-0003-1252-7232

ceylanylmz88@gmail.com

Cite as/ Atıf: Kutlu, M.O, Yapıcı, A., Sivik, S., Yılmaz, C. (2020). Halk eğitim merkezlerindeki derslerde "öğrenen kontrolü stratejisinin" Kullanımı -Kahramanmaraş ili örneği-, Turkish Studies, 15(2), 1557-1570. https://dx.doi.org/10.29228/TurkishStudies.39586

Received/Geliş: 04 November/Kasım 2019

Accepted/Kabul: 25 April/Nisan 2020

Copyright $(C)$ INTAC LTD, Turkey

Checked by plagiarism software

Published/Yayın: 30 April/Nisan 2020

CC BY-NC 4.0
} 
Türkoğlu districts in Kahramanmaraş. As data collection tool; "Learner Control Use Strategy Scale" The Validity and Reliability of which conducted by Kutlu (2012:244-250) and which consists of 28 items and seven dimensions was used; to analyze the data Arithmetic Mean, Standard Deviation, Independent Groups t-test and One Way Analysis of Variance (ANOVA) techniques were used. Data in this study were collected in 2019As a result of the research, the educators working in Public Education Centers generally use LCS in their courses, especially the sub-dimensions of the related scale; "Individual Learning Responsibility Control (ILRC) and Determination of Learning Strategies (DLS)“ Always ", Decision Making Skills Control (DMSC) and Content Control (CC) dimensions were" Frequent". According to the "Branches" there were some differences," but, Education Status "and" Duration of Service of the trainers it was observed that there was no difference in the use of LCS.

\section{Structured Abstract: Introduction and Theoretical Framework}

Today, especially in developed countries, education systems are no longer limited to schools and education programs in the information society, highlight the principle of "continuity of learning". In this context, since the 20th century, the concepts of information society and globalization have been referred together as, "lifelong learning". It is used in the same sense with the concepts of "Continuing Education", "Lifelong Education" and "Adult Education" or "Public Education". Situated at the beginning of the Adult Education Centers Adult Education Institutions in Turkey, apart from formal education, as a non-formal education activity, output-oriented practical trainings are provided for adults, based on their interests, abilities and needs.

For many years, the teaching-learning styles have been devoted to a fossilized paradigm that says "students are looked as an empty glass, and teachers have to fill them up with enough water". It is characterized by teacher-centric classroom in which teachers are in the mode of knowledge dispensers rather than facilitators. A chalk-and-talk method - a monologue presentation - is the mainstay of this teaching paradigm, whether the students understand what they are saying or not (Nugroho, 2017:2)

Learning goals and activitiy are the focus within teacher-learner interactions (Shambaugh and Magliaro, 2006:7). The idea of communities of learners (Brown,1994, cited in Shambaugh and Magliaro, 2006:7) Learning involves problems that are relavant to the learner and frequently emerge during the learning activitiy.

Study and scholars such as Merill (1975, 1980, cited in Kinizie, 1990:6) defend that required to be given instructional control. In this context, Reigeluth (1983: 362), who presents the "Learner Control" strategy as one of the seven macro strategies he proposed in the ElaborationTheory of Instruction he developed, has the right level of authority to provide students with high motivation for their own learning and if given responsibility, it emphasizes that the effectiveness, efficiency and interest of teaching may increase.

In accordence with Merrill (1979, cited in Reigeluth and Stein, 1983:362); the concept of learner control alludes to its most extensive sense, to the flexibility of learner to require command of the determination and sequencing of: (1) the substance to be learned (substance control); (2) the rate at which he or she will learn (pace control); (3) the specific intructional-strategy components he or she chooses and the arrange in which they are utilized (display control); and (4) the specific cognitive procedures the learner employments when association with the instruction (percepient cognitive control). Merill (1979, cited in Reigeluth and Stein, 1983:362) has portrayed the characteristics of each of these sorts of control, as well as the confinements that instruction places on each. The eleboration hypothesis gives posibilities of learner control over the determination of substance (1), informative-strategy components (2), and cognitive procedures (3). (The next category, pace, is as it were controllable at the miniaturized scale level).

The goal of this study is to look at whether the 'Learner Control Strategy' which has been particularly emphasized in formal education after between 1990, is utilized in nonformal instruction institutions providing grown-up instruction and preparing and whether there's a contrast in their utilize of learner control technique agreed to their branches, benefit periods and instructive status. The 
expanding significance of grown-up instruction in improved and improving nations will be fulfilled by well prepared instructors, and this can be based on the see that grown-ups have personal contrasts.

\section{Method}

In the research screening model, it is a descriptive study (Karasar, 2006:79). The study population of the research is educators (master trainers) working in Public Education Centers in Kahramanmaraş in 2019, and the working group; 129 trainers working in Public Education Centers in Onikişubat and Türkoğlu districts of Kahramanmaraş. As the method of determining the sample; Easy Access / Appropriate Sampling Method was used (Fraenkel and Wallen, 1993: 89).

As a data collection tool in the research; The "Learner Control Usage Strategy Scale", consisting of 28 items and seven dimensions, was conducted by the Validity and Reliability Study Kutlu (2012: 244-250).

\section{Findings}

While the educators within the scope of the research are the most in the field of handicrafts (41.1\%), at least in the other fields $(27.1 \%)$, they have a similar service in terms of duration of service, but they have a service period of maximum 6-10 years ( It is understood that they have the most education level in secondary education $(58.1 \%)$ in terms of education level $(29.5 \%)$.

As a result of the research, educators working in Public Education Centers generally use LCS in their lessons, especially the sub-dimensions of the relevant scale; "Individual Learning Responsibility Control (ILRC) and Determination of Learning Strategies (DLS) dimensions,“ Always ”, Decision Making Skills Control (DMSC) and Content Control (CC) dimensions were frequently included. When the points received by the instructors in using the ÖKS in the lessons are analyzed according to the branch variable, there is a significant difference between the master teachers who have the handicraft technology branch and the clothing production technology branch in favor of the master educators with the handicraft technology branch, and according to the "Educational Status" and "Service Periods".

\section{Discussion, Conclusion and Suggestions}

In this research, the levels of learner control strategy usage of educators (master teachers) working in Public Education Centers were examined in terms of various variables. Results obtained, it was determined that these educators' level of using learner control strategy is generally quite "sufficient". The basic reasons for this situation are the fact that the students in the Public Education Centers are from adult learners, they come to this education because of their interest, desires and needs, and that in this type of education defined as nonformal education, the tendency of adults to include their own knowledge and experiences in the learning processes is realized at higher levels and it can be said that it originated. As Kutlu (2012: 244-250) stated, the learning process is not a passive taking process, but an interaction process where the teacher and the student should be active together. Learning is generally defined as all relatively permanenet changes in potantial for behavior that result from experience but are not due to fatique, maturation, drugs, injury, or disease (Lefrançois, 2000: 5). In this regard, Senemoğlu (2013: 94) defines learning as a relatively permanent track change in the behaviors resulting from life. The experience here is all of the knowledge, skills and attitudesvalues that the person gains by perceiving and showing activity directly.

On the other hand, the opinions of the educators regarding the use of Learning Strategy according to their "branches" observe that there is a result in favor of the educators in the handicraft branch among the educators in the handicraft industry and educators in the clothing-production technology. In other words, the fact that the various cultural values that the learners have in teaching processes and their skills and knowledge related to these values form a connection in terms of handicrafts can be cited as a reason for the outcome. Nevertheless, Turkish society is closely modeled with learning-by-living modules with handicraft modules, as a result of learning from master-apprentice relationship, which is called a kind of cognitive apprenticeship, in transferring various cultural values to future generations, as a result of learning from passive participants to active practitioners and daily life skills and its relevance explains the present situation.

As a result of the research, it can be suggested that trainers working in public education centers should be given continuous in-service trainings on modern teaching methods and techniques, and that trainees should be trained on effective and productive learning with seminars at the beginning of the academic year. 
Keywords: Adult Education, Lifelong Learning, Learner Control, Detailed Sequencing Theory, Public Education.

Öz: Öğretim bilimi alanı öğretim yöntemlerinin geliştirilmesi ve anlaşılmasıyla ilgilidir. Bu disiplin alanı öğretimin daha kalıcı, daha kolay ve az zamanda gerçekleştirilmesini, öğretim sırasında motivasyonun üst düzeylerde gerçekleştirilmesini sağlamaya çalışır (Reigeluth and Stein, 1983:338).1983 yılında Reigeluth ve Merrill tarafından geliştirilen Öğretimi Ayrıntılı Sıralama Kuramının (The Elaboration Theory of Instruction) amacı da Merrill'in Öğeleri Belirleme Kuramını (Component Display Theory) makro düzeye (örneğin; ilişkili içerğin seçimi, sıralanması, sentezlenmesi ve sistematik olarak gözden geçirilmesi) yaymak, ve öğrenme ve öğretimle ilgili bilgileri bir araya getirmektir (Reigeluth and Stein, 1983:337). Diğer taraftan Reigeluth ve Stein'e göre (1983:362) Ayrıntılı Sıralama Kuramı öğrenenlere (1) içerik kontrolü, (2) öğretim stratejileri (3), ve bilişsel stratejiler (4) ile ilgili kontrol fırsatı veriR, ikinci strateji olan, adım kontrolü, ise sadece mikro düzeydedir. Bu araştırmanın genel amacı; Halk Eğitim Merkezlerinde görev yapan eğitimcilerin (usta öğreticilerin) derslerinde "Öğrenen Kontrolü Stratejini” hangi düzeyde kullandıklarının incelenmesidir. Araştırma tarama modelinde bir çalışmadır (Karasar, 2006:77). Araştırmanın çalışma evreni 2018-2019 eğitim öğretim yılı bahar döneminde Kahramanmaraş ilindeki Halk Eğitimi Merkezlerinde görev yapan eğitimciler (usta öğreticiler) olup, çalışma grubu ise; Kahramanmaraş’a bağlı Onikişubat ve Türkoğlu ilçelerindeki Halk Eğitimi Merkezlerinde görev yapan 129 eğitimcidir. Araştırmada veri toplama aracı olarak; geçerlik ve güvenirlik çalışması Kutlu (2012: 244-250) tarafindan yapılan, 28 madde ve yedi boyuttan oluşan "Öğrenen Kontrolü Kullanımı Stratejisi Ölçeği” (ÖKKSÖ), verilerin analizinde ise; betimleyici istatistiksel teknikler ile Bağımsız Örneklemeler t- testi ve Tek Yönlü Varyans Analizi (ANOVA) teknikleri kullanılmıştır. Bu çalışmadaki veriler 2019 yılında toplanmıştır. Araştırma sonucunda Halk Eğitim Merkezlerinde görev yapan eğitimcilerin derslerinde genellikle ÖKS'yi kullandıkları, özellikle de ilgili ölçeğin alt boyutlarından olan; "Bireysel Öğrenme Sorumluluğu Kontrolü (BÖSK) ve Öğrenme Stratejilerinin Belirlenmesi (ÖSB) boyutlarına; "Her Zaman”, Karar Verme Becerilerini Kontrol (KVBK) ile İçerik Kontrolü (İK) boyutlarına ise "Sık Sık” yer verdikleri görülmüştür. Eğitimcilerin derslerde ÖKS’yi kullanmalarında; "Branşlarına” göre bazı farklılıklar olduğu belirlenirken, "Öğrenim Durumlarına" ve "Hizmet Sürelerine" göre ise, herhangi bir farklılığın olmadığı görülmüş̧ür.

Anahtar Kelimeler: Öğrenen Kontrolü, Öğretimi Ayrıntılı Sıralama Kuramı, Halk Eğitimi, Yetişkin Eğitimi, Yaşamboyu Öğrenme.

\section{Giriş ve Problem}

Günümüzde, eğitim alanında yapılan bilimsel çalışmalar sonucunda elde edilen bilimsel bilgi birikimi, uygulamada karşılaşılan sorunların çözümünde oldukça etkili bir şekilde kullanımaktadır. Özellikle gelişmiş ülkelerde eğitim sistemleri artık sadece örgün eğitim sistemi içinde yer alan okullarla sınırlı değildir ve eğitimin sürekliliği önemli bir olgu olarak belirginleşmeye başlamıştır. Hatta ileri düzeyde eğitim almış bireylerin bile kendilerini geliştirmeye ihtiyaçları vardır. Ayrıca bilgi toplumunda eğitim programları, "öğrenmenin sürekliliğì" ilkesini ön plana çıkarmaktadır. Bu bağlamda 20. yüzyıldan itibaren "Yaşam Boyu Öğrenme (Lifelong Learning)" kavramları birlikte anılmaktadır. Örneğin, son yıllarda eğitimde her kademede uygulanmaya başlanan ve sürekli öğrenmeyi vurgulayan yapılandırmacı (constructivist) yaklaşımın Amerika ve Kanada gibi birçok ülkede kabul görmesi, geliştirilen eğitim programlarını da etkiliyor olması, yapılandırmacı anlayışın gelecekte de toplumların eğitim sistemlerini etkileyeceğine işaret etmektedir (Fer ve Cırık, 2007:20). Bu durum öğretimin sürekliliği ilkesi temelinde oluşturulan Halk Eğitimi Merkezlerindeki eğitim-öğretim süreçlerini de etkilemektedir. Eğitim-öğretim sistemleri içinde yaygın eğitim alt başlığı altında yer alan Halk Eğitimi Merkezlerinde, daha çok yetişkinlere yönelik, onların ilgi, yetenek ve ihtiyaçlarını temel alan, nisbeten kısa süreli uygulamaya dönük eğitimler verilmektedir. Ülkemizde "Halk Eğitimi" olarak bilinen bu tür eğitimler diğer ülkelerde; "Sürekli Eğitim Uygulamaları" ve "Yaşam Boyu Eğitim ve Öğretim" ve "Yetişkinlerin Eğitimi" kavramları ile aynı anlamda kullanılmaktadır. Halk Eğitimi Merkezlerinin temel amacı; örgün eğitimden 
yararlanamayan özellikle yetişkin bireylerin gerekli bilgi ve becerileri edinebilmesini sağlamaktır. Başka bir anlatımla Halk Eğitimi Merkezlerinde yetişkinlere yönelik olarak verilen eğitimler; öğretimin genel olarak okul dışı uygulamalarını oluşturan tve yetişkinler için düzenlenen planlı ve programlı başka bir anlatımla Formal Eğitim etkinlikleridir. UNESCO (1985) yetişkin eğitiminin örgün öğretim sisteminin dışında olan kişilerin geliştirilmesini amaçlayan ve onların ihtiyaçlarına göre hazırlanan bir eğitim türü olduğunu belirtmektedir. Kurt'a göre (2000:2) Halk eğitimi ya da yaygın eğitimin temel amacı örgün eğitim dışında kalan bireyleri tıpkı örgün eğitimde olduğu gibi toplumsallaşmalarını yardım ederek ülkeninm sosyal, kültürel ve ekonomik kalkınmaya hizmet etmelerini sağlayacak şekilde donatmaktır.

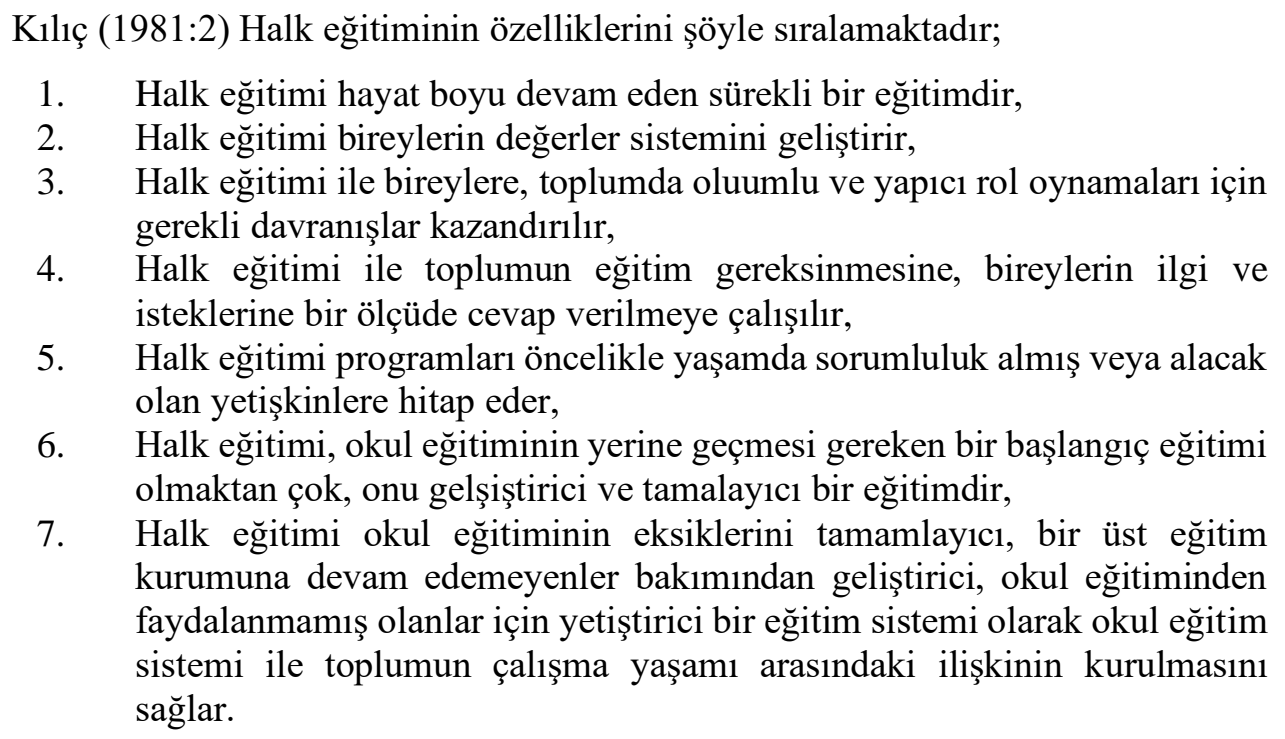

Son yıllarda öğretmenlerin temel sorumluluklarından biri de öğrencilerini, tanıyıp, onların potansiyellerinin en üst düzeylere ulaşmalarına yardım etmektir (Fer ve Cırık, 2007:20). Ancak mevcut müfredat programlarının temelinde hazırlanmış olan ders kitapları kullanılarak öğrencilerin derslere pasif katılımına neden olan geleneksel yaklaşımları kullanan öğretmen sayısı da oldukça fazladır (Fer ve Cırık,2007:20). Okullarımızda uygulanan öğretmen merkezli geleneksel öğretim ortamı etkinliklerinde dersler öğretmen sunumuna dayalı olarak işlenmektedir (Fer ve Cırık, 2007: 20). Derslerde sadece önceden hazırlamış olduğu içeriği öğrencilerine aktaran rolündeki öğretmen ve ağırlıkla olarak sadece ders kitabına bağlı düzelnemiş bir öğretim sürec; yaratıcı, eleştiren, yorumlayan ve öğrendiklerini gerçek yaşamda kullanabilen öğrenciler yetiştirmede başarısız olmuştur (Arslan, 2007:44).

Diğer taraftan, Tüm dünyada olduğu gibi ülkemizde de eğitim sistemini 2004-2005 y1lından itibaren etkilemeye başlayan "Yapılandırmacı Öğrenme Kuramı" son yıllarda eğitim uygulamalarını en çok etkileyen yaklaşımlardan biri olmuştur (Arslan, 2007:43; Özkan 2012:47). Yapılandırmac1 bir çerçeve, öğretmenleri kendilerinin ve öğrencilerinin düşünmeye ve keşfetmeye teşvik edildiği ortamları oluşturmaya zorlar (Brooks and Brooks, 1999: 30).

Bu bağlamda, “Öğrenci Kontrolü” stratejisini, Öğretimi Ayrıntılı Sıralama Kuramı’nda öğretim sürecinde uygun koşullarda kullanılmasını önerdiği yedi makro stratejiden biri olarak sunan Reigeluth (1987:258, Akt. Hoffmann, 1997:60), eğer motivasyonları yeterli olan olan öğrencilere kendi öğrenme süreçlerinde uygun düzeyde yetki ve sorumluluk verilirse, öğretimin niteliğinin artırılabileceğini vurgulamaktadır.

Öğrenen kontrolü, öğrenenlerin eğitim sırasında yöntem, zamanlama, uygulama ve geribildirimleri seçebilme derecesini ifade eder (Milheim ve Martin, 1991). "Öğrenen kontrolünün" geleneksel eğitim uygulamalarına göre en büyük avantajı, öğrencilerin kendi hızlarında, kendi 
ihtiyaçları ve tercihleri tarafından kontrol edilen eğitime devam etmelerini sağlama potansiyelidir (Eom \& Reiser, 2000). Kendi düzenini ayarlayabilme becerileri, öğrencinin kontrollü öğrenimden faydalanma becerisini etkileyebilecek bir öğrenci özelliğidir (Armstrong, 1989; Eom \& Reiser, 2000).

Uygun bir düzeyde öğrenen kontrolü stratejisi kullanımın temelinde öğrenciye içerik ve öğretim stratejilerini seçme ve sıralamasında seçenekler sunulması ve böylece ona kendi öğrenecekleri üzerinde kontrol olanağının verilmesidir (Hoffmann,1997:61).

Merrill'e göre (1979; Akt. Reigeluth and Stein: 1983: 362); öğrenen kontrolü stratejisinin uygulanmasının adımları; genel olarak öğretmenlerin öğrencilerine tercihlerini göz önünde bulundurarak gerçekleştirilebilir. Bu adımlar; (1) öğrenilecek olan içeriğin seçimi (içerik kontrolü), (2) Öğrencinin öğreneceği içeriğin miktarının seçimi (adım veya hız kontrolü), (3) Uygulanacak olan öğretim stratejilerinin seçimi (strateji belirleme), (4) Öğrencinin kendi öğrenmesinde kullanacağı kendisine özgü bilişsel stratejilerinin seçimi ve sıralanması (bilincli bilişsel kontrol) başlıklarıyla listelenebilir. Bu strateji öğrenen merkezli öğrenme yaklaşımlarına uygundur. Oysa okullarda daha çok öğretmen merkezli, öğrenciyi pasifize eden yöntem ve teknikler kullanılmakta, bunun sonucunda öğrenme etkili, verimli ve ilgi çekici olmaktan uzak bir görünüm oluşturmaktadır.

\section{Amaç}

$\mathrm{Bu}$ araştırmanın temel amacı; Halk Eğitim Merkezlerinde görev yapan eğitimcilerin "Öğrenen Kontrolü Stratejisini Kullanma Düzeylerini” belirlemektir.

Araştırmada bu temel amaç doğrultusunda aşağıdaki sorulara cevap aranmıştır;

1) Halk Eğitimi Merkezindeki eğitimcilerin öğrenen kontrolü stratejisini kullanmaları ne düzeydedir?

2) Halk Eğitimi Merkezindeki eğitimcilerin öğrenen kontrolü stratejisini kullanmalarında branşlarına göre farklılıklar var mıdır?

3) Halk Eğitimi Merkezindeki eğitimcilerin öğrenen kontrolü stratejisini kullanmlarında hizmet sürelerine göre farklılıklar var mıdır?

4) Halk Eğitimi Merkezindeki eğitimcilerin öğrenen kontrolü stratejisini kullanmalarında ögrenim durumlarına göre farklılıklar var mıdır?

\section{Önem}

Yaşamın farklı dönemlerinde temel eğitim oldukça önemliyken sonraki dönemlerde yetişkin eğitimi daha fazla önem arz etmektedir. Eğitimin temel işlevlerinden biri de yetişkinlerin gelişen topluma uyumlarını sağlayacak şekilde eğitmektir. Bu araştırmayla son yıllarda örgün eğitimdeki eğitim-öğretim süreçlerinde özellikle vurgulanan "Öğrenci Merkezli Eğitimin” yetişkinlere yönelik eğitim-öğretim hizmeti veren yaygın eğitim kurumlarındaki uygulanma düzeyini incelenmektir. Özellikle Ggelişmekte olan ülkelerde yetişkin eğitiminin artan öneminin ancak iyi yetişmiş öğretmenler tarafından karşılanacağ 1 genell,ikle kabul görmekte olup, bunun nedeninin yetişkinlerin bireysel farklı1ıklarının olması görüşüne dayandırılmıştır. $\mathrm{Bu}$ araştırma ile Halk Eğitimi Merkezleri'nde verilmekte olan eğitim-öğretim süreçlerinde öğrenen merkezli "Yapılandırmacı Öğrenme Kuramının" uygulanmasına yönelik bir farkındalık oluşturabileceği, böylece bu kurumlarda daha etkili ve verimli öğrenmelerin gerçekleştirilmesine yönelik çalışmaların katk1 sağlaması beklenmektedir. 


\section{Metod}

\section{Araştırmanın modeli}

Araştırma, betimsel türde tarama modelinde bir çalışmadır. Tarama modelleri, herhangi bir durumu var olduğu şekliyle betimlemeyi amaçlayan, başka bir anlatımla mevcut duruma herhangi bir müdahalede bulunmayan araştırma yaklaşımlarıdır (Karasar, 2006:77). Bu modellerde araştırılacak olan konular değiştirilmeden tanımlanmaya çalışlılır (Karasar, 2006:77). Bu araştırmada da, Halk Eğitimi Merkezlerindeki eğitim-öğretim süreçlerinde eğitimcilerin derslerinde öğrenen kontrolü stratejisini kullanma düzeyleri çeșitli değișkenler açısından incelenmiș ve olduğu şekliyle betimlenmeye çalıșılmıştır.

\section{Çalışma grubu}

Araştırmanın çalışma grubunda; 2018-2019 eğitim-öğretim yılı bahar döneminde Kahramanmaraş ili Onikişubat ve Türkoğlu ilçelerindeki Halk Eğitimi Merkezlerinde görev yapan 129 eğitimci yer almıştır. $\mathrm{Bu}$ eğitimcilerin belirlenmesinde ve veri toplama araçlarının uygulanmasında, bu makalenin yazarlarından birinin Kahramanmaraş Türkoğlu Halk Eğitimi Merkezinde yönetici yardımcısı olarak çalışıyor olması uygulamada bazı kolaylıklar sağlamıştır. Bu nedenle örneklemin belirleme yöntemi olarak; Kolay Ulaş1labilir/Uygun Örneklem Yöntemi (Eassy Accessebile/Convenience Sampling Model) kullanılmıştır (Fraenkel ve Wallen, 1993:89).

\section{Çalışma Grubuna Uygulanan Ölçek}

Verilerin toplanmasında; I. Bölümünde; "Kişisel Bilgi Formu" ve 2. Bölümünde ise; “Öğrenen Kontrolü Stratejisi Kullanım Düzeyleri” olmak üzere iki bölüm halinde Kutlu (2012:244250) tarafından geliştirilmiş olan veri toplama ölçeği kullanılmıştır.

I. Bölüm: Kişisel Bilgi formu; Eğitimcilerin çeşitli kişisel bilgilerini tespit edebilmek amacıyla araştırmacılar tarafından geliştirilmiştir. $\mathrm{Bu}$ formda öğreticilerin demografik özelliklerini belirlemeye yönelik sorular yer almaktadır.

II. Bölüm: Öğrenen Kontrolü Stratejisi Kullanım Ölçeği: Bu bölüm toplam 28 madde ve 7 boyuttan oluşmaktadır. Bu ölçeğin Geçerlik ve Güvenirlik Çalışması Kutlu (2012:244-250) tarafindan yapılmıştır. Ölçeğin boyutları; (1) USÇBK: Uygun Strateji ve Çalışma Becerilerinin Kullanımı, (2) UBUHK: Uygun Bilgiyi Uygun Hizda Kontrol, (3) KVBK: Karar Verme Becerilerini Kontrol, (4) İK: İçerik Kontrolü, (5) BMK: Bilgi Miktarının Kontrolü, (6) BÖSK: Bireysel Öğrenme Sorumluluğu Kontrolü ve (7) ÖSB: Öğrenme Stratejilerinin Belirlenmesi şeklindedir.

Beşli likert tipinde olan ölçeğin maddeleri; "Hiçbir Zaman"= 1 Puan, "Bazen"= 2 Puan, "Sıklıkla"= 3 Puan, "Genellikle"= 4 Puan ve "Her Zaman"= 5 puan şeklinde sıralanmıştır. Puanlama açısından ölçekten alınan yüksek puanlar katılımcıların öğrenen kontrolü stratejisini kullanma yaklaşımlarının yüksek düzeyde olduğunu, düşük puanlar ise öğrenen kontrolü stratejisini kullanma yaklaşımlarının oldukça az seviyede olduğunu göstermektedir. Araştırmacılar tarafından gerekli izinler alındıktan sonra ölçek eğitimcilere uygulanmış ve bu kapsamda ölçeğin Cronbach Alpha güvenirlik katsayısı tekrar belirlenmiştir. Gerçekleştirilen analizler sonucunda; Cronbach Alpha güvenirlik katsayısı ölçeğin geneli için .79 olarak hesaplanmıştır. Ölçeğin faktör bazında Cronbach Alpha güvenirlik katsayıları incelendiğinde ise ; USÇBK için .58, UBUHK için .65, KVBK için .72, İK için .31, BMK için .64, BÖSK için .40 ve ÖSB için .20 olarak hesaplanmıştır. Nunally, (1978; Akt. Baştürk, 2014:43), C. Alpha katsayısının .70 ve üzeri olmasını güvenilir olarak ifade etmiştir. Bu referansa dayalı olarak ölçeğin güvenilir olduğu (.79) söylenebilir. Diğer taraftan katsayının yüksekliği ölçme aracının güvenirliğinin ve tek boyutluğunun bir göstergesidir ancak katsayının düşük olması hemen güvenirliğin düşük olduğu şeklinde yorumlanmamalıdır. Eğer çok boyutluluk söz konusu ise katsayı düşük de çıkabilir (Baştürk, 2014:43). 


\section{Verilerin Çözümlenmesi}

Araştırmada kullanılması planlanan ölçek uygulandıktan sonra elde edilen ham veriler SPSS veri kayıt ortamına aktarılmış, yani veriler sisteme girilmiştir. Bu işlem sırasında katılımcılardan 8 tanesinin veri toplama araçlarını eksik doldurduğu tespit edilmiş ve araştırmaya dâhil edilmemiştir. Bilgisayar ortamına aktarılan veriler SPSS-17 Programı ile analiz edilmiştir. İstatistiksel işlemlerin uygulanmasında anlamlılık düzeyi (.05) olarak kabul edilmiştir. Araştırmada elde edilen verilerin normal dağ $11 \mathrm{~mm}$ gösterip göstermediği Kolmogorov Smirnov testi kullanılarak belirlenmiş olup, basıklık ve çarpıklık katsayıları, histogram ve Q-Q grafikleri ile incelenmiştir. Sonuç olarak "Öğrenen Kontrolü Stratejisi Kullanımı Ölçeğinin" normal dağılım gösterdiği belirlenmiştir $(\mathrm{KS}=.088, \mathrm{P}>.05)$. Verilerin analizinde bazı merkezi eğilim ve yayılım ölçüleri, bağımsız gruplar ttesti, tek yönlü varyans analizi (ANOVA) ve Bonferroni anlamlılık çözümleme testi kullanılmıştır.

\section{Bulgular}

Araştırmanın bu bölümünde; ilk olarak arştırmaya katılan eğitimcilerin kişisel bilgileri belirlenmiştir (Tablo:1). Daha sonra bu eğitimcilerin derslerinde öğrenen kontrolü stratejisini kullanımlarının ne düzeyde olduğu belirlenmiştir. Ayrıca bu eğitimcilerin "Öğrenen Kontrolü Stratejisini Kullanma Düzeylerinin"; (1) Branş (Tablo:2), (2) Hizmet Süresi (Tablo:3) ve (3) Öğrenim Durumu (Tablo:4) değişkenlerine göre anlamlı bir fark olup-olmadığına yönelik bulgular yer almaktadır.

Araştırmaya katılan öğreticilerin demografik özellikleri Tablo 1'de sunulmuştur.

Tablo 1: Öğrencilerin Demografik Özelliklere Göre Frekans Ve Yüzde Dağılımları.

\begin{tabular}{cccc}
\hline Değişken & Gruplar & $\boldsymbol{f}$ & $\boldsymbol{\%}$ \\
\hline \multirow{2}{*}{ Branş } & Giyim Üretim Teknolojisi & 41 & 31,8 \\
& El Sanatları & 53 & 41,1 \\
& Diğer & 35 & 27,1 \\
\hline \multirow{3}{*}{ Hizmet Süresi } & $1-5$ yıl & 29 & 22.5 \\
& $6-10$ yıl & 38 & 29,5 \\
& $11-15$ y1l & 33 & 25,6 \\
& 16 yll ve üzeri & 29 & 22,5 \\
\hline \multirow{2}{*}{ Öğrenim Durumu } & Ortaöğretim & 75 & 58,1 \\
& Yükseköğretim & 54 & 41,9 \\
\hline
\end{tabular}

Tablo 1 incelendiğinde; araştırmaya katılan eğitimcilerin; branş olarak, en fazla el sanatları alanından $(\% 41,1)$, en az diğer alanlarda (güzellik ve saç bakım hizmetleri-görsel sanatlar-sporbilgisayar teknolojisi-sağl1k- müzik ve gösteri sanatları-çocuk gelişimi ve eğitimi-aşçl1ık) $(\% 27,1)$ oldukları, Hizmet Süresi açısından genel olarak benzerlik göstermekle beraber, en fazla 6-10 y1l arasında hizmet sürelerinin olduğu $(\% 29,5)$, Öğrenim Durumu bakımından ise; en fazla ortaöğretim düzeyinde öğrenim durumuna sahip oldukları $(\% 58,1)$, anlaşılmıştır.

Araştırmanın birinci alt probleminde "Halk Eğitimi Merkezlerindeki eğitimcilerin derslerinde ÖKS kullanmaları hangi seviyededir?" sorusuna verilen cevaplarla ilgili bilgiler Tablo 2 'de verilmiştir. 
Tablo 2: Halk Eğitimi Merkezindeki Eğitimcilerin Öğrenen Kontrolü Stratejisi Kullanımlarının Genel Analiz Sonuçları

\begin{tabular}{ccccccc}
\hline Ölçek/Alt Boyutlar & $\mathbf{N}$ & $\overline{\mathbf{X}}$ & ss & Max & Min & Düzey \\
\hline ÖKSK & 129 & 103.20 & 12.75 & 139.00 & 76.00 & Genellikle \\
\hline USÇBK & 129 & 20.63 & 3.95 & 30.00 & 13.00 & Genellikle \\
\hline UBUHÖK & 129 & 22.55 & 4.18 & 30.00 & 12.00 & Genellikle \\
\hline KVBK & 129 & 19.66 & 4.06 & 30.00 & 9.00 & Sik Sik \\
\hline İK & 129 & 13.12 & 2.95 & 20.00 & 5.00 & Sik Sık \\
\hline BMK & 129 & 5.85 & 2.64 & 10.00 & 2.00 & Sik Sık \\
\hline BÖS & 129 & 8.45 & 1.60 & 10.00 & 3.00 & Her Zaman \\
\hline ÖSB & 129 & 8.83 & 1.29 & 10.00 & 4.00 & Her Zaman \\
\hline
\end{tabular}

ÖKSK: Öğrenen Kontrolü Stratejisi Kullanımı Ölçeği / USÇBK: Uygun Strateji ve Çalışma Becerilerinin Kullanımı / UBUHÖK: Uygun Bilgiyi Uygun Hızda Öğrenme Kontrolü / KVBK: Karar Verme Becerilerini Kontrol / İK: İçerik Kontrolü / BMK: Bilgi Miktarının Kontrolü / BÖS: Bireysel Öğrenme Sorumluluğu / ÖSB: Öğrenme Stratejilerinin Belirlenmesi.

Tablo 2 incelendiğinde; eğitimcilerin ÖKSK'nın geneline $(\bar{X}=103.20)$ ve USÇBK $(\bar{X}=20.63)$, UBUHÖK ( $\overline{\mathrm{X}}=22.55)$ "genellikle"; KVBK ( $\overline{\mathrm{X}}=19.66)$, IK ( $\overline{\mathrm{X}}=13.12), \mathrm{BMK}(\overline{\mathrm{X}}=5.85)$ "slk slk"; BÖS $(\overline{\mathrm{X}}=8.45)$, ÖSB $(\overline{\mathrm{X}}=8.83)$ boyutlarına ilişkin olarak "her zaman" düzeyinde görüş bildirdirmişlerdir.

Araştırmanın ikinci alt probleminde "Halk Eğitimi Merkezlerindeki eğitimcilerin derslerinde öğrenen kontrolü stratejisini kullanma düzeyleri katılımcıların uzmanlık alanlarına göre değişip değişmediği araştırılmış ve elde edilen tek yönlü varyans analizi (ANOVA) sonuçları Tablo 3'te verilmiştir. 
Tablo 3: Halk Eğitimi Merkezindeki Eğitimcilerin Derslerinde “Öğrenen Kontrolü Stratejisi Kullanma Düzeylerinin” Eğitimcinin uzmanlık alanına göre belirlenmesiyle ilgili Tek Yönlü Varyans Analizi (Anova) Sonuçları

\begin{tabular}{|c|c|c|c|c|c|c|c|c|c|c|}
\hline $\begin{array}{l}\text { Ölçek/Alt } \\
\text { Boyutlar }\end{array}$ & Branş & $\mathbf{N}$ & $\overline{\mathbf{X}}$ & SS & VK & KT & sd & $\mathbf{F}$ & $\mathbf{p}$ & Bonf \\
\hline \multirow{3}{*}{ ÖKSK } & Giyim & 41 & 99.02 & 13.12 & GA & 1048.93 & 2 & \multirow{3}{*}{3.346} & \multirow{3}{*}{$.038^{*}$} & \multirow{3}{*}{$2>1$} \\
\hline & El Sanat. & 53 & 105.19 & 11.17 & GI & 19749.83 & 126 & & & \\
\hline & Diğer & 35 & 105.09 & 13.70 & Top & 20798.76 & 128 & & & \\
\hline \multirow{3}{*}{ USÇBK } & Giyim & 41 & 19.98 & 4.11 & GA & 27.07 & 2 & \multirow{3}{*}{.868} & \multirow{3}{*}{.422} & \multirow{3}{*}{ - } \\
\hline & El Sanat. & 53 & 21.04 & 3.23 & Gí & 1965.07 & 126 & & & \\
\hline & Diğer & 35 & 20.77 & 4.68 & Top & 1992.14 & 128 & & & \\
\hline \multirow{3}{*}{ UBUHÖK } & Giyim & 41 & 21.59 & 3.93 & GA & 73.10 & 2 & \multirow{3}{*}{2.129} & \multirow{3}{*}{.123} & \multirow{3}{*}{ - } \\
\hline & El Sanat. & 53 & 22.64 & 4.05 & Gİ & 2162.83 & 126 & & & \\
\hline & Diğer & 35 & 23.54 & 4.51 & Top & 2235.92 & 128 & & & \\
\hline \multirow{3}{*}{ KVBK } & Giyim & 41 & 18.80 & 3.93 & GA & 46.17 & 2 & \multirow{3}{*}{1.406} & \multirow{3}{*}{.249} & \multirow{3}{*}{-} \\
\hline & El Sanat. & 53 & 19.92 & 3.69 & Gİ & 2068.82 & 126 & & & \\
\hline & Diğer & 35 & 20.26 & 4.67 & Top & 2114.99 & 128 & & & \\
\hline \multirow{3}{*}{ İK } & Giyim & 41 & 13.20 & 2.79 & GA & 2.117 & 2 & \multirow{3}{*}{.120} & \multirow{3}{*}{.887} & \multirow{3}{*}{ - } \\
\hline & El Sanat. & 53 & 13.21 & 2.75 & GI & 1111.90 & 126 & & & \\
\hline & Diğer & 35 & 12.91 & 3.46 & Top & 1114.02 & 128 & & & \\
\hline \multirow{3}{*}{ BMK } & Giyim & 41 & 5.00 & 2.61 & GA & 54.73 & 2 & \multirow{3}{*}{4.117} & \multirow{3}{*}{$.019^{*}$} & \multirow{3}{*}{$3>1$} \\
\hline & El Sanat. & 53 & 5.96 & 2.59 & Gİ & 837.47 & 126 & & & \\
\hline & Diğer & 35 & 6.69 & 2.52 & Top & 892.20 & 128 & & & \\
\hline \multirow{3}{*}{ BÖS } & Giyim & 41 & 7.88 & 1.94 & GA & 26.53 & 2 & \multirow{3}{*}{5.546} & \multirow{3}{*}{$.005 * *$} & \multirow{3}{*}{$2>1$} \\
\hline & El Sanat. & 53 & 8.94 & 1.17 & Gİ & 301.39 & 126 & & & \\
\hline & Diğer & 35 & 8.37 & 1.54 & Top & 327.92 & 128 & & & \\
\hline \multirow{3}{*}{ ÖSB } & Giyim & 41 & 8.56 & 1.47 & $\frac{1}{\mathrm{GA}}$ & 4.35 & 2 & \multirow{3}{*}{1.318} & \multirow{3}{*}{.271} & \\
\hline & El Sanat. & 53 & 8.94 & 1.10 & Gİ & 207.90 & 126 & & & - \\
\hline & Diğer & 35 & 8.97 & 1.32 & Top & 212.25 & 128 & & & \\
\hline
\end{tabular}

*p $<.05 \quad * * \mathrm{p}<.01$

ÖKSK: Öğrenen Kontrolü Stratejisi Kullanımı Ölçeği / USÇBK: Uygun Strateji ve Çalışma Becerilerinin Kullanımı / UBUHÖK: Uygun Bilgiyi Uygun Hızda Öğrenme Kontrolü / KVBK: Karar Verme Becerilerini Kontrol / İK: İçerik Kontrolü / BMK: Bilgi Miktarının Kontrolü / BÖS: Bireysel Öğrenme Sorumluluğu / ÖSB: Öğrenme Stratejilerinin Belirlenmesi.

Tablo 3'ten anlaşılacağı üzere; araştırmaya katılan eğitimcilerin 41'i giyim-üretim teknolojisi alanı, 53'ü el sanatları teknolojisi ve 35'i diğer alan branşlarına sahiptir. Eğitimcilerin ölçeğin genelinden ve alt boyutlarından aldıkları puanlar branş değişkenine göre incelendiğinde; ÖKSK' nın genelinde ve BÖS alt boyutunda el sanatları teknolojisi branşı ve giyim üretim teknolojisi branşına sahip olan usta öğreticiler arasında el sanatları teknolojisi branşına sahip usta öğreticiler lehine anlaml fark bulunmuştur $(\mathrm{F}(2,126)=3.346 ; \mathrm{p}=.038<.05)$ ve $(\mathrm{F}(2,126)=5.546 ; \mathrm{p}=.005<.05)$. Ayrıca BMK alt boyutunda ise; giyim üretim teknolojisi branşı ve diğer branşlara sahip olan usta öğreticiler arasında diğer alan branşına sahip usta öğreticiler lehine anlamlı fark bulunmuştur $(\mathrm{F}(2,126)=4.117 ; \mathrm{p}=.019<.05)$. Fakat USÇBK $(\mathrm{F}(2,126)=.868 ; \mathrm{p}=.422>.05)$ ve UBUHÖK $(\mathrm{F}(2,126)=2.129 ; \mathrm{p}=.123>.05), \quad \mathrm{KVBK} \quad(\mathrm{F}(2,126)=1.406 ; \mathrm{p}=.249>.05), \quad$ İ $\quad(\mathrm{F}(2,126)=.120$; $\mathrm{p}=.887>.05)$ ve ÖSB $(\mathrm{F}(2,126)=1.318 ; \mathrm{p}=.271>.05)$ alt boyutlarında branş değişkenine göre anlamlı farklılaşmaya rastlanmamıştır.

Araştırmanın üçüncü alt probleminde "Halk Eğitimi Merkezlerindeki eğitimcilerin öğrenen kontrolü stratejisini kullanımlarında kıdemlerine göre farklılık var mıdır?" sorusuna yanıt aranmış ve tek yönlü varyans analizi (ANOVA) sonuçları Tablo 4'te verilmiştir. 
Tablo 4: Halk Eğitimi Merkezindeki Eğitimcilerin Derslerinde Öğrenen Kontrolü Stratejisi Kullanmalarının Hizmet Süresi Değişkenine Göre belirlenmesiyle ilgili olarak belirlenen Tekli Varyans Analizi (ANOVA) Sonuçları

\begin{tabular}{|c|c|c|c|c|c|c|c|c|c|c|}
\hline $\begin{array}{l}\text { Ölçek/Alt } \\
\text { Boyutlar }\end{array}$ & $\begin{array}{l}\text { Hizmet } \\
\text { Süresi }\end{array}$ & $\mathbf{N}$ & $\overline{\mathbf{X}}$ & SS & VK & KT & sd & $\mathbf{F}$ & $\mathbf{p}$ & Bonf \\
\hline \multirow{4}{*}{ ÖKSK } & $1-5 \mathrm{y} 1 \mathrm{l}$ & 29 & 102.07 & 13.25 & & & & \multirow{4}{*}{.639} & \multirow{4}{*}{.591} & \multirow{4}{*}{ - } \\
\hline & $6-10$ yil & 38 & 103.50 & 14.16 & GA & 314.208 & 3 & & & \\
\hline & $11-15 \mathrm{y} 1 \mathrm{l}$ & 33 & 101.61 & 12.12 & Gl & 20484.55 & 125 & & & \\
\hline & 16 yıl ve üzeri & 29 & 105.76 & 11.11 & & & & & & \\
\hline \multirow{4}{*}{ USÇBK } & $1-5 \mathrm{yll}$ & 29 & 20.90 & 4.49 & & & & \multirow{4}{*}{1.702} & \multirow{4}{*}{.170} & \multirow{4}{*}{ - } \\
\hline & $6-10$ y1l & 38 & 20.66 & 4.03 & GA & 78.164 & 3 & & & \\
\hline & $11-15 \mathrm{y} 11$ & 33 & 19.45 & 3.03 & GI & 1913.97 & 125 & & & \\
\hline & 16 yıl ve üzeri & 29 & 21.66 & 4.03 & & & & & & \\
\hline \multirow{4}{*}{ UBUHÖK } & $1-5 \mathrm{y} 1 \mathrm{l}$ & 29 & 21.83 & 3.90 & & & & \multirow{4}{*}{.439} & \multirow{4}{*}{.725} & \multirow{4}{*}{ - } \\
\hline & 6-10 yıl & 38 & 22.87 & 3.88 & GA & 23.338 & 3 & & & \\
\hline & $11-15$ y 11 & 33 & 22.48 & 4.60 & Gl & 2212.58 & 125 & & & \\
\hline & 16 yıl ve üzeri & 29 & 22.93 & 4.44 & & & & & & \\
\hline \multirow{4}{*}{ KVBK } & $1-5$ yll & 29 & 19.41 & 4.45 & & & & \multirow{4}{*}{.389} & \multirow{4}{*}{.761} & \multirow{4}{*}{ - } \\
\hline & $6-10$ yıl & 38 & 19.50 & 4.75 & GA & 19.570 & 3 & & & \\
\hline & $11-15$ y1l & 33 & 19.42 & 3.61 & Ul & 2095.42 & 125 & & & \\
\hline & 16 yıl ve üzeri & 29 & 20.38 & 3.20 & & & & & & \\
\hline \multirow{4}{*}{ İK } & $1-5 \mathrm{y} 11$ & 29 & 12.83 & 2.71 & & & & \multirow{4}{*}{.809} & \multirow{4}{*}{.491} & \multirow{4}{*}{ - } \\
\hline & 6-10 y1l & 38 & 13.03 & 3.50 & GA & 21.213 & 3 & & & \\
\hline & $11-15$ y1l & 33 & 12.85 & 2.41 & Gl & 1092.80 & 125 & & & \\
\hline & 16 yıl ve üzeri & 29 & 13.86 & 2.97 & & & & & & \\
\hline \multirow{4}{*}{ BMK } & $1-5 \mathrm{y} 1 \mathrm{l}$ & 29 & 5.90 & 2.13 & & & & \multirow{4}{*}{.223} & \multirow{4}{*}{.880} & \multirow{4}{*}{ - } \\
\hline & $6-10$ y1l & 38 & 6.05 & 2.65 & $G A$ & $\begin{array}{l}4.140 \\
887.15\end{array}$ & 3 & & & \\
\hline & $11-15$ y1l & 33 & 5.55 & 3.10 & Ui & $\begin{array}{l}881.45 \\
892,20\end{array}$ & 125 & & & \\
\hline & 16 yıl ve üzeri & 29 & 5.90 & 2.62 & & & & & & \\
\hline \multirow{4}{*}{ BÖS } & $1-5$ yll & 29 & 8.97 & 1.09 & & & & \multirow{4}{*}{1.602} & \multirow{4}{*}{.192} & \\
\hline & $6-10$ yıl & 38 & 8.42 & 1.67 & GA & 12.139 & 3 & & & \\
\hline & $11-15$ y1l & 33 & 8.09 & 1.84 & Gl & $315 . / 8$ & 125 & & & - \\
\hline & 16 yıl ve üzeri & 29 & 8.38 & 1.59 & & & & & & \\
\hline & 1 - 5 y1l & 29 & 8.55 & 1.45 & & & & & & \\
\hline ÖSR & $6-10$ y1l & 38 & 8.84 & 1.20 & GA & $\begin{array}{l}4.537 \\
20771\end{array}$ & $\begin{array}{c}3 \\
125\end{array}$ & 010 & 438 & \\
\hline USB & $11-15$ y1l & 33 & 9.09 & 1.10 & Gl & 21224 & 125 & . & .4J0 & - \\
\hline & 16 yıl ve üzeri & 29 & 8.79 & 1.42 & & & & & & \\
\hline
\end{tabular}

$* \mathrm{p}<.05$

ÖKSK: Öğrenen Kontrolü Stratejisi Kullanımı Ölçeği / USÇBK: Uygun Strateji ve Çalışma Becerilerinin Kullanımı / UBUHÖK: Uygun Bilgiyi Uygun Hızda Öğrenme Kontrolü / KVBK: Karar Verme Becerilerini Kontrol / IKK: İçerik Kontrolü / BMK: Bilgi Miktarının Kontrolü / BÖS: Bireysel Öğrenme Sorumluluğu / ÖSB: Öğrenme Stratejilerinin Belirlenmesi

Tablo 4'ten anlaşılacağı üzere; araştırmaya katılan eğitimcilerin 29'u 5 yıl ve altı, 38'i 6-10 y1l, 33'ü 11-15 y1l ve 29'u 16 y1l ve üzeri hizmet süresine sahiptir. Eğitimcilerin ölçeğin genelinden ve alt boyutlarından aldıkları puanlar hizmet süresi değişkenine göre incelendiğinde; ÖKSK'nın genelinde $(\mathrm{F}(3,125)=.639 ; \mathrm{p}=.591>.05)$ ve USÇBK $(\mathrm{F}(3,125)=1.702 ; \mathrm{p}=.170>.05)$, UBUHÖK $(\mathrm{F}(3,125)=.439 ; \mathrm{p}=.725>.05) \quad$ ve $\mathrm{KVBK} \quad(\mathrm{F}(3,125)=.389 ; \mathrm{p}=.761>.05)$, İK $\quad(\mathrm{F}(3,125)=.809 ;$ $\mathrm{p}=.491>.05)$, BMK $(\mathrm{F}(3,125)=.223 ; \mathrm{p}=.880>.05)$, BÖS $(\mathrm{F}(3,125)=1.602 ; \mathrm{p}=.192>.05)$ ve ÖSB $(\mathrm{F}(3,125)=.910 ; \mathrm{p}=.438>.05)$ alt boyutlarının tamamında hizmet süresi değişkenine göre anlamlı farklılaşmaya rastlanmamıştır. 
Araştırmanın dördüncü alt probleminde "Halk Eğitimi Merkezindeki Usta Öğreticilerin öğrenen kontrolü stratejisini kullanımları öğrenim durumuna göre farklılık göstermekte midir?" sorusuyla ilgili bağımsız gruplar t-testi sonuçları Tablo 5'te verilmiştir.

Tablo 5: Halk Eğitimi Merkezindeki Eğitimcilerin Derslerinde Öğrenen Kontrolü Stratejisi Kullanımlarının Öğrenim Durumu Değişkenine Göre Bağımsız Gruplar T-Testi Sonuçları

\begin{tabular}{|c|c|c|c|c|c|c|c|}
\hline Ölçek/Alt Boyutlar & $\begin{array}{l}\text { Öğrenim } \\
\text { Durumu }\end{array}$ & $\mathbf{N}$ & $\overline{\mathbf{X}}$ & SS & sd & $\mathbf{t}$ & $\mathbf{p}$ \\
\hline \multirow{2}{*}{ ÖKSK } & Ortaöğretim & 75 & 103.60 & 12.02 & \multirow{2}{*}{127} & \multirow{2}{*}{.417} & \multirow{2}{*}{.677} \\
\hline & Yükseköğretim & 54 & 102.64 & 13.80 & & & \\
\hline \multirow{2}{*}{ USÇBK } & Ortaöğretim & 75 & 20.59 & 3.81 & \multirow{2}{*}{127} & \multirow{2}{*}{-.139} & \multirow{2}{*}{.889} \\
\hline & Yükseköğretim & 54 & 20.69 & 4.16 & & & \\
\hline \multirow{2}{*}{ UBUHÖK } & Ortaöğretim & 75 & 22.85 & 4.01 & \multirow{2}{*}{127} & \multirow{2}{*}{.970} & \multirow{2}{*}{.334} \\
\hline & Yükseköğretim & 54 & 22.13 & 4.40 & & & \\
\hline \multirow{2}{*}{ KVBK } & Ortaöğretim & 75 & 19.20 & 4.03 & \multirow{2}{*}{127} & \multirow{2}{*}{-1.519} & \multirow{2}{*}{.131} \\
\hline & Yükseköğretim & 54 & 20.30 & 4.07 & & & \\
\hline \multirow{2}{*}{$\dot{\mathrm{I} K}$} & Ortaöğretim & 75 & 13.16 & 2.88 & \multirow{2}{*}{127} & \multirow{2}{*}{.163} & \multirow{2}{*}{.871} \\
\hline & Yükseköğretim & 54 & 13.07 & 3.07 & & & \\
\hline \multirow{2}{*}{ BMK } & Ortaöğretim & 75 & 5.93 & 2.73 & \multirow{2}{*}{127} & \multirow{2}{*}{.407} & \multirow{2}{*}{.684} \\
\hline & Yükseköğretim & 54 & 5.74 & 2.53 & & & \\
\hline \multirow{2}{*}{ BÖS } & Ortaöğretim & 75 & 8.39 & 1.63 & \multirow{2}{*}{127} & \multirow{2}{*}{-.525} & \multirow{2}{*}{.601} \\
\hline & Yükseköğretim & 54 & 8.54 & 1.56 & & & \\
\hline \multirow{2}{*}{ ÖSB } & Ortaöğretim & 75 & 8.69 & 1.43 & \multirow{2}{*}{127} & \multirow{2}{*}{-1.421} & \multirow{2}{*}{.158} \\
\hline & Yükseköğretim & 54 & 9.02 & 1.04 & & & \\
\hline
\end{tabular}

$* \mathrm{p}<.05$

ÖKSK: Öğrenen Kontrolü Stratejisi Kullanımı Ölçeği / USÇBK: Uygun Strateji ve Çalışma Becerilerinin Kullanımı / UBUHÖK: Uygun Bilgiyi Uygun Hızda Öğrenme Kontrolü / KVBK: Karar Verme Becerilerini Kontrol / İK: İçerik Kontrolü / BMK: Bilgi Miktarının Kontrolü / BÖS: Bireysel Öğrenme Sorumluluğu / ÖSB: Öğrenme Stratejilerinin Belirlenmesi

Tablo 5'te görüldüğü üzere; araştırmaya 75 ortaöğretim ve 54 yükseköğretim düzeyinde öğrenime sahip usta öğretici katılmıştır. Usta öğreticilerin ölçeğin genelinden ve alt boyutlarından aldıkları puanlar öğrenim düzeyi değişkenine göre incelendiğinde; ÖKSK'da $(\mathrm{t}(127)=.417$, $\mathrm{p}=.677>.05)$ ve USÇBK $(\mathrm{t}(127)=-.139, \mathrm{p}=.889>.05)$, UBUHÖK $(\mathrm{t}(127)=.970, \mathrm{p}=.334>.05), \mathrm{KVBK}$ $(\mathrm{t}(127)=-1.519, \mathrm{p}=.131>.05)$, IK $(\mathrm{t}(127)=.163, \mathrm{p}=.871>.05)$, BMK $(\mathrm{t}(127)=.407, \mathrm{p}=.684>.05)$, BÖS $(\mathrm{t}(127)=-.525, \mathrm{p}=.601>.05)$ ve ÖSB $(\mathrm{t}(127)=-1.421, \mathrm{p}=.158>.05)$ alt boyutlarının tamamında öğrenim durumu değişkenine göre anlamlı bir farklılaşmaya rastlanmamıştır.

\section{Tartışma ve Sonuç}

Araştırma kapsamında, Halk Eğitimi Merkezlerindeki görev yapan eğitimcilerin (usta öğreticilerin) derslerinde öğrenen kontrolü stratejisi kullanma düzeyleri çeşitli değişkenler açısından incelenmiştir. Elde edilen sonuçlara göre; bu eğitimcilerin öğrenen kontrolü stratejisi kullanma düzeylerinin genellikle oldukça "yeterli" düzeyde olduğu belirlenmiştir. Başka bir ifadeyle, Halk Eğitimi Merkezlerinde (HEM) görev yapan eğitimcilerin derslerinde öğrencilerinin kendi öğrenme süreçlerini bizzat kendilerinin yönetmeleri için onlara belirli bir düzeyde de olsa özerklik vermekte olduğu görülmüştür. Bu durumun temel nedenleri; genel olarak HEM'lerdeki öğrencilerin yetişkin öğrenenlerden olması, bu eğitime ilgi, istek ve ihtiyaçları nedenleriyle geliyor olmaları ve yaygın eğitim olarak tanımlanan bu eğitim türünde, yetişkinlerin kendi bilgi ve deneyimlerini öğrenme süreçlerine dâhil etme eğilimlerinin daha üst düzeylerde gerçekleşiyor olması gibi faktörlerden kaynaklandığı söylenebilir. Kutlu'nun da (2012:244) belirttiği gibi, öğrenme süreci pasif bir alma 
süreci değil, fakat öğretmen ve öğrencinin beraberce aktif olması gereken bir etkileşim sürecidir. Zaten literatür incelendiğinde, öğrenmenin hemen hemen tüm tanımlarında "deneyim/yaşantı" kavramı özellikle vurgulanmaktadır (Lefrançois, 2000:4). Bu konuda Senemoğlu da (2013:94) öğrenmeyi; yaşantı sonucu oluşan davranışlardaki nispeten kalıcı izli değişiklik olarak tanımlamaktadır. Buradaki yaşantı kişinin algılayarak ve doğrudan doğruya etkinlik göstererek elde ettiği bilgi, beceri ve tutum-değerlerin tümüdür. Yaşantı bireyin çevresiyle etkileşimi sonucunda bireyde kalan izlenim ve birikimler olup etkileşim olarak da ifade edilebilir.

Araştırma sonucunda Halk Eğitim Merkezlerinde görev yapan eğitimcilerin derslerinde genellikle ÖKS'yi kullandıkları, özellikle ilgili ölçeğin alt boyutlarından olan "Bireysel Öğrenme Sorumluluğu Kontrolü (BÖSK)" ve "Öğrenme Stratejilerinin Belirlenmesi (ÖSB)" boyutlarına "Her Zaman", "Karar Verme Becerilerini Kontrol (KVBK)" ile "İçerik Kontrolü (IK)" boyutlarına ise "S1k S1k" bu stratejiye yer verdikleri görülmüştür. Diğer taraftan, eğitimcilerin "branşlarına" göre Öğrenme Stratejisi Kullanımına ilişkin görüşleri ise; el sanatları alanındaki eğitimciler ile giyimüretim teknoloji alanındaki eğitimciler arasında el sanatları branşındaki eğitimcilerin lehine bir sonucun olduğu görülmektedir. Başka bir anlatımla; öğretim süreçlerinde; öğrenenlerin sahip olduğu çeşitli kültürel değerlerin ve bu değerlere ilişkin yetenek ve bilgi birikimlerinin el sanatları açısından bir bağlantı oluşturması durumu ortaya çıkan sonuç açısından gerekçe olarak gösterilebilir. Bununla birlikte Türk toplumunun gelecek nesillere çeşitli kültürel değerleri aktarmada bir çeşit bilişsel çıraklık olarak adlandırılan usta-çırak ilişkisiyle öğretimin gerçekleşmesi öğrenenlerin pasif birer katılımcıdan, aktif birer uygulayıcıya doğru yönelmeleri sonucunda, el sanatları ile ilgili modüllerin yaparak-yaşayarak öğrenmeye örnek olması ve günlük yaşam becerileri ile yakından ilişkili olması mevcut durumu açılar niteliktedir.

Araştırmadan elde edilen diğer bulgulara göre; eğitimcilerin öğrenen kontrolü stratejisi kullanma düzeyleri arasında branşlarına göre bazı farklılıkların olduğu görülürken, hizmet yılı ve ögrenim durumu değişkenleri bakımından anlamlı bir farklılaşmaya rastlanmamıştır. Bu durumun temel nedeni; Halk Eğitimi Merkezlerindeki öğretme-öğrenme süreçlerinin ve yaygın eğitimin temel özelliğinin zaten öğrenenlerin yaparak-yaşayarak, etkin katılımı gerçekleştirmeleri, yaratıcı düşünme becerilerini yoğun olarak kullanmaları, öğrenmeyi aktif olarak gerçekleştirmelerinin bir sonucudur. $\mathrm{Bu}$ eğitim türünde eğitimciler daha çok yol göstericidirler.

\section{Öneriler}

1. Halk eğitimi merkezlerinde görev yapan eğitimcilere çağdaş öğretim yöntem ve teknikleri konularında sürekli olarak Hizmet-içi Eğitimler verilmelidir,

2. Halk Eğitimi Merkezlerinde öğrenim gören öğrenciler, öğretim dönemleri başında seminerlerle etkili ve verimli öğrenme konularında eğitilmelidir,

3. Halk Eğitimi Merkezlerindeki Yaygın Eğitim Faaliyetlerinin kalitesinin daha da iyileştirilmesi için işlevsel çalışmalar yapılmalı, bu tür eğitimlere daha geniş bütçeler ayrılmalıdır.

\section{Kaynakça}

Armstrong, A. M. (1989). Persistence and the causal perception of failure: Modifying cognitive attributions. Journal of Educational Psychology, 70(2), 154-166,

Arslan, M.(2007). Eğitimde Yapılandırmacı yaklaşımlar, Ankara Üniversitesi Eğitim Bilimleri Fakültesi Dergisi, cilt:40, sayı:1, 41-61,

Baştürk, S.(2014). Eğitimde Ölçme ve Değerlendirme, Nobel Kitabevi, 2014, Ankara,

Brooks, J.M.; Brooks, M. G.(1999). The Case For Constructivist Classrooms, Merrill Prentice Hall, Upper Saddle River, NJ, Columbus, Ohio, 
Eom, W. \& Reiser, R. A. (2000). The effects of self-regulation and instructional control on performance and motivation in computer-based instruction. International Journal of Instructional Media, 27(3), pp. 247-261,

Fer S.; Cırık, İ.(2007). Yapılandırmacı Öğrenme, Kuramdan Uygulamaya, Morpa Yayıncılık, İstanbul,

Fraenkel, J.R.; Wallen, N.E. (1993). How to Design and Evaluate Research in Education, Second Edition, McGraw-Hill Inc, NY,

Hoffman, S.(1997). "Elaboration theory and hypermedia: Is There a Link?", Educational Technology, Vol.3,1,pp.57-64,

Karasar, N. (2006). Bilimsel Araştırma Yöntemi, 16. Baskı, Nobel Yayın Dağıtım. Ankara,

K1lıç. E.(1981). Halk Eğitiminde Kuram ve Uygulama, Orta Doğu Amme İdaresi Enstitüsü Yayınları, No:190, Ankara,

Kinzie, M.B. (1990). Requirements and benefits of effective interactive instruction: Learner control, self-regulation, and continuing motivation, Educational Technology Research and Development, Vol.38, no.1, pp.5-21, Springer,

Kutlu, M.O. (2012).” Developing a scale on the usage of learner control strategy", Educational Research and Reviews, Vol.7 (10), pp.244-250,

Kurt, İ.(2000). Yetişkin Eğitimi, Nobel Yayınevi, Ankara,

Lefrançois, G.R.(2000). Theories of Human Learning, Fourth Edition, Wadsworth/Thomson Learning, Belmont, Canada,

Milheim, W. D., \& Martin, B. L. (1991). Theoretical bases for the use of learner control: Three different perspectives. Journal of Computer Based Instruction, 18(3), 99105,

Nugroho, A. 2017. Contemporary Teaching and Learning. Reform (53), University of Muhammadiyah Malang,

Özkan, H.H.(2012). Yapılandırmacı Odaklı Öğretim tasarımı Modeli Örneği, Balıkesir Üniversitesi Sosyal Bilimler Enstitüsü Dergisi, Cilt: 15, Sayı:28, 47-

Reigeluth.C. M. (1983). Instructional-Design Theories and Models, Lawrence Erlbaum Associates, Publishers, Hillsdale, NJ,

Reigeluth, C. \& Stein, F.S. (1983). "The elaboration theory of instruction", In C. Reigeluth (ed.), Instructional Design Theories and Models, Lawrence Erlbaum Associates, Publishers, Hillsdale, NJ: Hillsdale, NJ,

Senemoğlu, N.(2013). Gelişim, Öğrenme ve Öğretim Kuramından Uygulamaya, Ankara, Yarg1 Yayınevi,

Shambaugh, N.; Magliaro, S.G.(2006). Instructional Design, Pearson Education, Inc., NY, 